\title{
INVESTIGASI ZONA AKUIFER MENGGUNAKAN METODE GEOLISTRIK KONFIGURASI SCHLUMBERGER DI PANTAI PARANGLUHU KECAMATAN BONTOBAHARI, KABUPATEN BULUKUMBA
}

\author{
Wahyuni $^{1}$, Jamaluddin ${ }^{2 *}$, Sabrianto Aswad ${ }^{1}$, La Ode Armin ${ }^{1}$ \\ ${ }^{1}$ Program Studi Geofisika, Fakultas Matematika dan Ilmu Pengetahuan Alam, Universitas Hasanuddin. \\ ${ }^{2}$ Geological Engineering, School of Geosciences, China University of Petroleum (East China), Qingdao, China. \\ *Penulis koresponden. Alamat email: jamaljamaluddin1994@gmail.com
}

\begin{abstract}
Abstrak
Air merupakan sumberdaya alam yang sangat penting bagi kebutuhan makhluk hidup, khususnya manusia. Airtanah paling banyak di manfaatkan karena memenuhi standar pemenuhan air bersih dan layak pakai. Walaupun demikian terdapat perbedaan kondisi dan kualitas airtanah di berbagai wilayah, salah satunya di wilayah pesisir yang dapat menyimpan airtanah payau - asin. Hal ini banyak terjadi di berbagai wilayah salah satunya wilayah kepesisiran Kecamatan Bontobahari. Terkait kondisi tersebut, penelitian ini dilakukan dengan tujuan untuk mengetahui karakteristik akuifer dan persebaran airtanah asin di Wilayah Kepesisiran Kecamatan Bontobahari, Kabupaten Bulukumba. Metode yang digunakan dalam penelitian ini adalah pendugaan geolistrik menggunakan konfigurasi Schlumberger. Berdasarkan hasil pengukuran dan pengolahan data, nilai resistivitas yang menunjukkan akuifer berkisar antara 29,4 - 36,1 $\Omega \mathrm{m}$ dan dapat ditemukan pada kedalaman 6,50 $19,7 \mathrm{~m}$.
\end{abstract}

Kata kunci: Akuifer, Geolistrik, Resistivitas, Schlumberger.

\begin{abstract}
Water is a natural resource that is essential for needs of living things, especially human beings. Most groundwater widely utilized because the standards compliance of clean water and proper use. However there is a difference in the conditions and quality of the groundwater in different areas, one of which on the territory of coastal zone that can store brackish ground water - salty. This is a lot going on in various parts of the territory of one of the coastal zone subdistrict of Bontobahari. Related conditions, this research was conducted with the aim to find out the characteristics of the aquifer and the salty soil water distribution in the region of coastal zone subdistrict of Bontobahari, Bulukumba. The methods used in this research is the geoelectric resistivity injection using the Schlumberger configuration. Based on the measurement and data processing, resistivity values of aquifer have about $29,4-36,1 \Omega \mathrm{m}$ and it can be found at a depth of $6,50-19,7 \mathrm{~m}$.
\end{abstract}

Key Words : Aquifer, Geoelectric, Resistivity, Schlumberger.

\section{Pendahuluan}

Airtanah merupakan salah satu sumber daya alam yang sangat penting bagi kehidupan masyarakat. Sebagai sumber utama air bersih, kebutuhan masyarakat terhadap airtanah semakin meningkat sejalan dengan pemahaman masyarakat akan pentingnya penggunaan air bersih dalam kehidupan sehari-hari. Di kegiatan industri, air bersih juga sangat dibutuhkan 
bagi kegiatan perindustrian sebagai roda penggerak industri.

Airtanah di Pesisir memiliki tingkat kerentanan yang tinggi terhadap pencemaran airtanah salah satunya adalah intrusi air laut. Air laut memiliki berat jenis yang lebih tinggi kira-kira 1.025 $\mathrm{g} / \mathrm{cm}^{3}$, sedangkan air tawar (fresh water) memiliki berat jenis $1.000 \mathrm{~g} / \mathrm{cm}^{3}$. Ketika terjadi penurunan muka airtanah di wilayah pesisir, maka air laut yang memiliki berat jenis lebih tinggi akan menyusup masuk kedalam airtanah. Sehingga menghasilkan zona pertemuan antara keduanya yang menyebabkan terjadi kontak dan percampuran yang diindikasikan sebagai zona dispersi (zone of dispersion) (Pinder \& Celia, 2006). Penurunan muka air laut dikarenakan dinamika pesisir yang terjadi pada masa lampau tidak hanya meninggalkan material endapan berupa pasir dan lumpur. Beberapa kemungkinan lain seperti tertinggalnya air laut dan terjebak di daratan kepesisiran juga mungkin terjadi. Air laut yang tertinggal di daratan lalu terjebak pada suatu cekungan dan membentuk jebakan air asin disebut connate water (Purnama, 2010).

Adapun metode geofisika yang dapat digunakan untuk menentukan letak akuifer airtanah adalah geolistrik dengan mempelajari sifat kelistrikan yang ada di bawah permukaan tanah. Metode geolistrik adalah resistivitas atau mengukur besar tahanan jenis batuan. Dalam upaya mencari resistivas batuan kita menginjeksikan arus dan tegangan dan melihat hasil dari injeksi tersebut. Besar tidaknya nilai resistivitas bergantung kepada besarnya pembacaan arus dan tegangan yang diinjeksikan serta jenis batuan yang dicari dari suatu pengukuran tersebut. Jumlah besar arus yang diinjeksikan bergantung kepada besar sumber daya listrik yang digunakan dalam pengukuran (Amin, 2016).

\section{Konfigurasi Geolistrik Schlumberger}

Metoda tahanan jenis merupakan metode geofisika yang dipakai untuk pengukuran tahanan jenis semu suatu medium. Pengukuran dengan konfigurasi Schlumberger ini menggunakan 4 elektroda, masing-masing 2 elektroda arus dan 2 elektroda potensial (Azhar dan Gunawan, 2003).

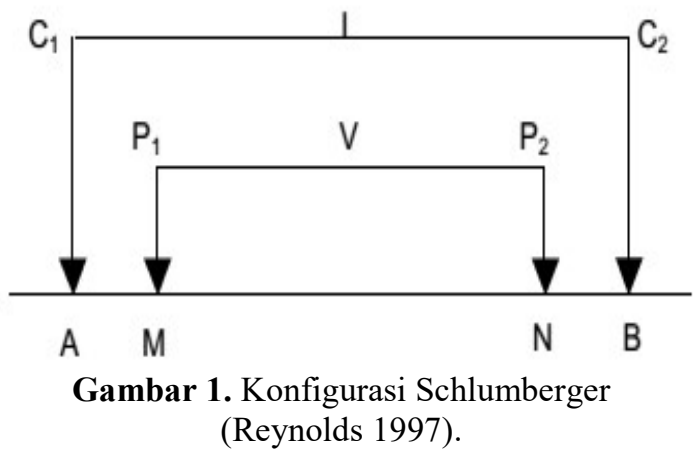

Tahanan jenis semu medium yang terukur dihitung berdasarkan persamaan (van Norstand et al, 1966; Reynolds 1997; Telford et al, 1990).

$$
\rho=K \frac{\Delta V}{I}
$$

Dengan :

$\mathrm{K}=2 \pi\left[\left(\frac{1}{\mathrm{AM}}-\frac{1}{\mathrm{MB}}\right)-\left(\frac{1}{\mathrm{AM}}-\frac{1}{\mathrm{MB}}\right)\right]^{-1}$

Dengan harga :

$$
\begin{aligned}
& \mathrm{MN}=\mathrm{a}(\text { spasi elektroda potensial }) \\
& \mathrm{AM}=\mathrm{NB}=\mathrm{n} \cdot \mathrm{a} \\
& \mathrm{MB}=\mathrm{AN}=(\mathrm{n}+1) \cdot \mathrm{a}
\end{aligned}
$$

Untuk konfigurasi Schlumberger, harga K dapat dihitung menggunakan persamaan (Azhar dan Gunawan, 2003) :

$$
\begin{aligned}
& \mathrm{K}=\mathrm{n} .(\mathrm{n}+1) \pi \mathrm{a} ; \\
& \mathrm{n}=1,2,3,4,5, \ldots \ldots \ldots
\end{aligned}
$$




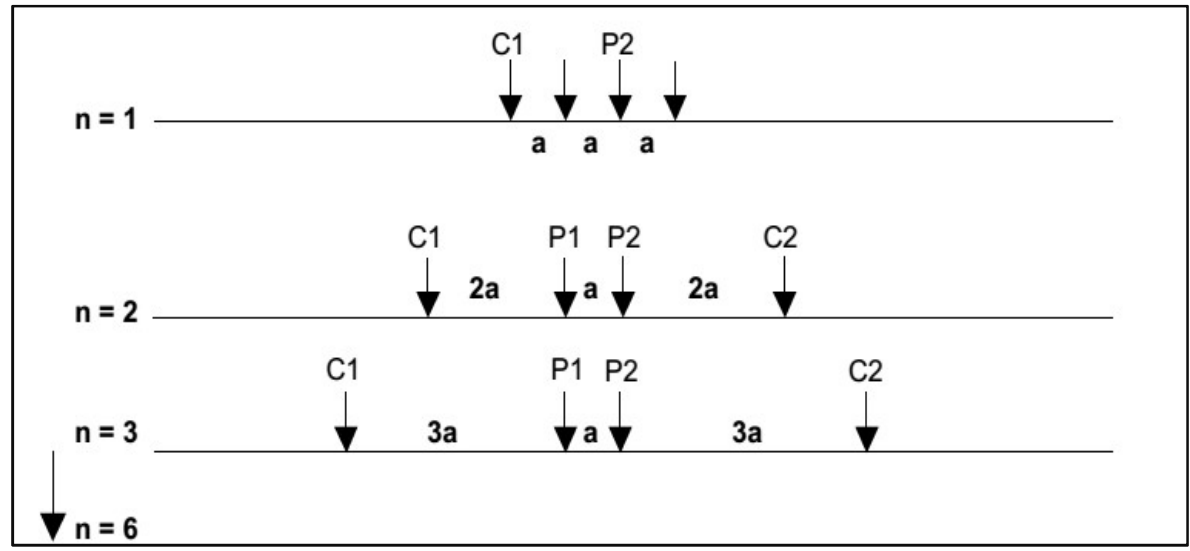

Gambar 2. Konfigurasi Schlumberger (Reynolds 1997).

dengan :

$\rho$ : Tahanan terukur (apparentresistivity)

$\Delta \mathrm{V}$ : Potensial yang terukur antara elektroda P1dan P2,

I : Arus listrik yang mengalir ke tanah melalui elektroda $\mathrm{C} 1$ dan $\mathrm{C} 2$,

$\mathrm{K}$ : Faktor geometri konfigurasi elektroda.

Tabel 1 Nilai resistivitas material material Bumi (Telford et al,, 1990)

\begin{tabular}{|c|c|}
\hline Material & $\begin{array}{c}\text { Resistivity } \\
\text { (Ohm-Meter) }\end{array}$ \\
\hline Air (Udara) & $0.01-100$ \\
\hline Pyrite (Pirit) & $500-800000$ \\
\hline Quartz (Kwarsa) & $1 \times 1012-1 \times 1013$ \\
\hline Calcite (Kalsit) & $30-1 \times 1013$ \\
\hline Rock Salt (Garam Batu) & $200-10000$ \\
\hline Granite (Granit) & $1.7 \times 102-45 \times 104$ \\
\hline Andesite (Andesit) & $200-100000$ \\
\hline Basalt (Basal) & $500-10000$ \\
\hline Limestoes (Gamping) & $200-8000$ \\
\hline Sandstone (Batu Pasir) & $20-2000$ \\
\hline Shales (Batu Tulis) & $1-1000$ \\
\hline Sand (Pasir) & $1-100$ \\
\hline Clay (Lempung) & $0.5-300$ \\
\hline Ground Water (Air Tanah) & 0.2 \\
\hline Sea Water (Air Asin) & $0.01-1000$ \\
\hline Magnetite (Magnetit) & $600-10000$ \\
\hline Dry Gravel (kerikil kering) & $10-800$ \\
\hline Alluvium (Aluvium) & $100-60$ \\
\hline Gravel (Kerikil) & \\
\hline
\end{tabular}

\section{Metode Penelitian}

Metodologi penelitian yang dilakukan adalah pemetaan geologi, pengambilan data geolistrik, dan juga pengukuran muka airtanah dangkal secara langsung pada lokasi penelitian. Pengukuran geolistrik untuk penyelidikan akuifer digunakan metode pengukuran resistivitas konfigurasi Schlumberger pada daerah penelitian. Konfigurasi Schlumberger ini dilakukan dengan cara mengukur besarnya kuat arus dan beda potensial dengan jarak elektroda yang berbeda. Setelah diperoleh data yang diperlukan, maka dilakukan pengolahan data. Untuk mengolah data geolistrik diperlukan software IPI2Win. IPI2Win adalah program computer yang secara automatis menentukan model resistivitas bawah permukaan dari data hasil survey geolistrik resistivitas.

\section{Hasil dan Pembahasan}

Hasil pengolahan data geolistrik single channel 1D dengan menggunakan program IPI2Win ditampilkan seperti Gambar 3. Dari hasil tersebut terlihat perbedaan resistivitas bawah permukaan, hal ini ditunjukkan adanya perbedaan nilai pada kolom pertama pada tabel. Untuk hasil pengolahan data konfigurasi sclumberger didapatkan RMS Error sebesar 7.79\% dan kedalaman tembus pendugaan sampai 
64.9 meter, dengan rentang resistivitas semu $(\rho)$ antara 5.69-2180 $\Omega \mathrm{m}$ (Gambar 4).

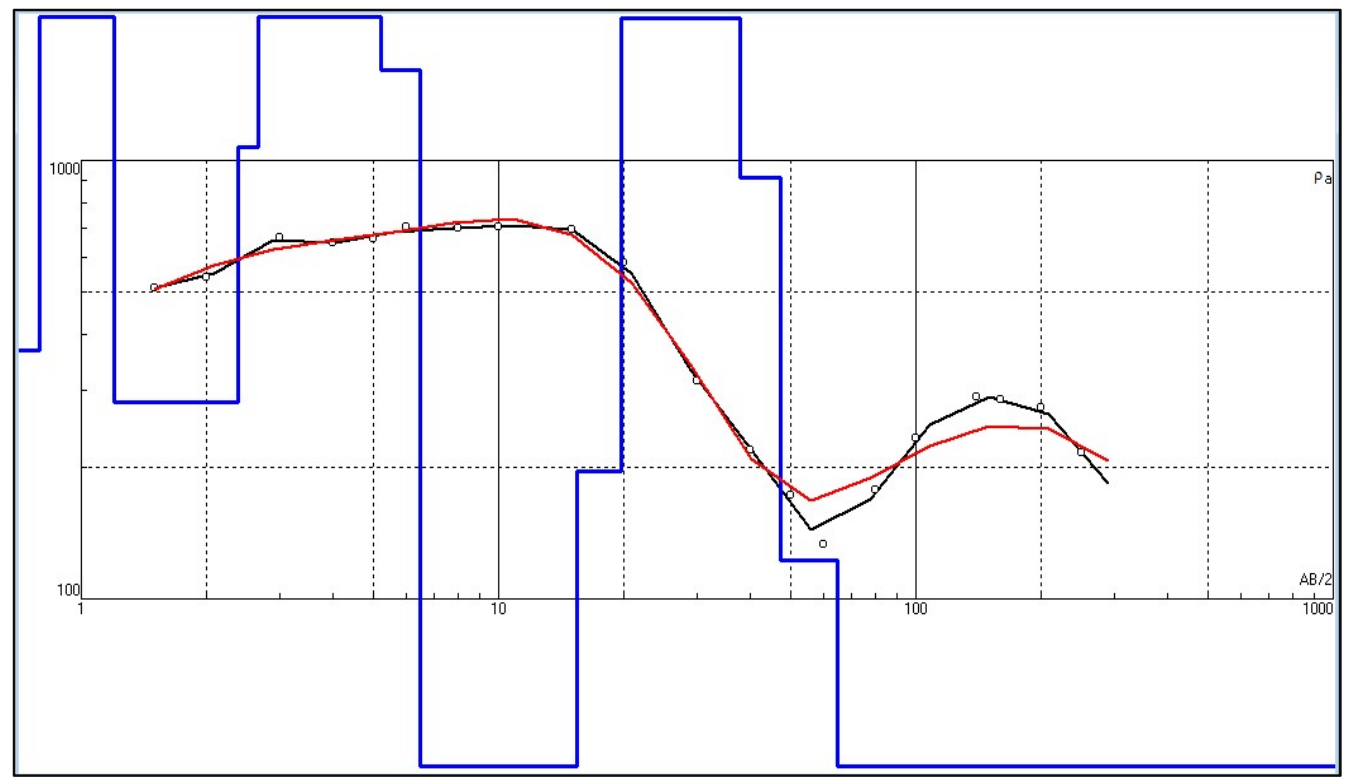

Gambar 3. Hasil inversi penampang 1D

\begin{tabular}{|c|c|c|c|c|}
\hline 用 & \multicolumn{2}{|c|}{ Error $=7.79 \%$} & 口 & 83 \\
\hline $\mathbf{N}$ & $\rho$ & h & d & Alt \\
\hline 3 & 281 & 1.18 & 2.38 & -2.381 \\
\hline 4 & 1070 & 0.274 & 2.66 & -2.655 \\
\hline 5 & 2180 & 2.57 & 5.23 & -5.226 \\
\hline 6 & 1602 & 1.28 & 6.5 & -6.501 \\
\hline 7 & 36.1 & 1.43 & 7.93 & -7.931 \\
\hline 8 & 29.4 & 7.45 & 15.4 & -15.38 \\
\hline 9 & 196 & 4.35 & 19.7 & -19.73 \\
\hline 10 & 2117 & 18.2 & 37.9 & -37.95 \\
\hline 11 & 915 & 9.46 & 47.4 & -47.41 \\
\hline 12 & 122 & 8.34 & 55.7 & -55.75 \\
\hline 13 & 122 & 9.17 & 64.9 & -64.92 \\
\hline 14 & 5.69 & & & \\
\hline
\end{tabular}

Gambar 4. Tabel hasil pengolahan data Resistivitas 1D Konfigurasi Sclumberger.

Secara umum resistivitas bawah permukaan dibagi menjadi 6 bagian lapisan, yang terdiri dari lapisan bagian atas (lapisan permukaan/tanah penutup) beserta Endapan Aluvium, Tufa, Batupasir dan Batugamping. Adapun penjelasan tiaptiap lapisan tanah/ batuan adalah sebagai berikut :
Lapisan pertama merupakan lapisan permukaan berupa lapisan tanah penutup beserta Endapan Aluvium dengan nilai resistivitas 62.4-281 $\Omega \mathrm{m}$. Lapisan ini merupakan lapisan tanah timbunan yang mengandung air tanah namun bisa meloloskan air ke dalam lapisan yang lebih dalam. Lapisan ini berada pada kedalaman $0,0-2,38$ meter.

$\checkmark$ Lapisan kedua diinterpretasikan sebagai lapisan batuan sedimen berupa Batugamping Terumbu dengan nilai resistivity 1070-2180 $\Omega \mathrm{m}$. Lapisan ini merupakan lapisan batuan bersifat Brittle oleh karena itu tidak dapat menyimpan air. Lapisan ini berada pada kedalaman 2,38-6,50 meter.

$\checkmark$ Lapisan ketiga diinterpretasikan sebagai lapisan batuan sedimen berupa Batupasir dengan nilai resistivity 29.4 - $36.1 \Omega \mathrm{m}$. Lapisan ini merupakan lapisan batuan mengandung air. Lapisan ini dapat menyerap air serta menyimpan air (lapisan akuifer dangkal). Lapisan ini berada pada kedalaman 6,50 - 19,7 meter. 


\begin{tabular}{|c|c|c|c|}
\hline $\begin{array}{c}\text { Kedalaman } \\
\text { (meter) }\end{array}$ & $\begin{array}{c}\text { Log } \\
\text { Litologi } \\
\end{array}$ & $\begin{array}{c}\text { Nilai Resistivitas } \\
\text { (ohm.m) }\end{array}$ & Deskripsi Batuan \\
\hline \multirow{2}{*}{2.38} & 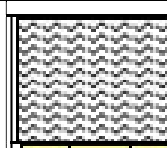 & $62.4-281$ & $\begin{array}{c}\text { Tanah Penutup (timbunan), permukaan } \\
\text { Endapan Aluvium, material lepas dan hasil } \\
\text { lapukan batugamping. }\end{array}$ \\
\hline & 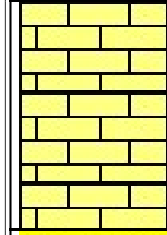 & $1070-2180$ & $\begin{array}{c}\text { Batugamping Terumbu, batuan sedimen } \\
\text { yang dapat menyerap air tetapi sukar untuk } \\
\text { menyimpan air karna jenis batuan tersebut } \\
\text { cenderung meloloskan air ke lapisan yang } \\
\text { ada dibawahnya. }\end{array}$ \\
\hline 6.50 & & $29.4-36.1$ & $\begin{array}{l}\text { Batupasir, batuan sedimen yang memiliki } \\
\text { permebilitas dan porositas baik untuk } \\
\text { Menyimpan air yang terserap lapisan } \\
\text { diatasnya. Lapisan tersebut bisa dikatakan } \\
\text { lapisan akuifer }\end{array}$ \\
\hline 19.7 & 等 & 196 & $\begin{array}{c}\text { Tufa, batuan vulkanik yang agak fresh dan } \\
\text { mempunyai pori, serta retakan batuan yang } \\
\text { terisi air akibat infiltrasi dari batugamping } \\
\text { yang berada di atasnya. }\end{array}$ \\
\hline 55.7 & & $915-2117$ & $\begin{array}{l}\text { Batugamping Terumbu, batuan sedimen } \\
\text { yang dapat menyerap air tetapi sukar untuk } \\
\text { menyimpan air karna jenis batuan tersebut } \\
\text { cenderung meloloskan air ke lapisan yang } \\
\text { ada dibawahnya. }\end{array}$ \\
\hline 64.9 & $\therefore \because \therefore \therefore$ & $5.69-122$ & $\begin{array}{l}\text { Batupasir, batuan sedimen yang } \\
\text { memiliki permebilitas dan porositas baik } \\
\text { untuk menyimpan air yang terserap lapisan } \\
\text { diatasnya. Lapisan tersebut bisa } \\
\text { dikatakan lapisan akuifer. }\end{array}$ \\
\hline
\end{tabular}

Gambar 5. Interpretasi susunan lapisan tanah dan batuan, kedalaman serta ketebalan lapisan berdasarkan nilai resistivity hasil pengukuran geolistrik.

Lapisan keempat diinterpretasikan sebagai lapisan batuan sedimen berupa Tufa dengan nilai resistivity $196 \Omega \mathrm{m}$. Lapisan ini merupakan lapisan batuan mengandung air yang relatif sedikit yang merupakan hasil dari infiltrasi dari Batugamping Terumbu yang berada diatasnya. Lapisan ini dapat menyerap air serta menyimpan air (lapisan akuifer). Lapisan ini berada pada kedalaman 19,7 - 37,9 meter.

$\checkmark$ Lapisan kelima diinterpretasikan sebagai lapisan batuan sedimen berupa Batugamping dengan nilai resistivity 915-2117 $\Omega \mathrm{m}$. Lapisan ini merupakan lapisan batuan yang mengandung air 
dan dapat menyerap air namun bisa meloloskan air ke dalam lapisan yang lebih dalam. Lapisan ini berada pada kedalaman 37,9 - 55,7 meter.

$\checkmark$ Lapisan terakhir diinterpretasikan sebagai lapisan batuan sedimen berupa Batupasir, dimana untuk range nilai resistivity 5.69-122 $\Omega \mathrm{m}$ merupakan lapisan batupasir yang mengandung air berada pada kedalaman 55,7-64,9 m. Lapisan ini juga merupakan lapisan batuan mengandung air dan dapat menyerap air serta menyimpan air (lapisan akuifer) yang merupakan akuifer yang menerus dari bagian permukaan dan mengisi akuifer dalam.

Berdasarkan pendekatan konseptual dan deterministic didapatkan akuifer pada daerah penelitian merupakan batupasir dengan nilai resistivitas $(20-50$ Ohm.m $)$ dengan kedalaman akuifer yang didapatkan terdiri dari akuifer dangkal dan dalam, akuifer dangkal mempunyai kedalaman pada tiap titik berkisar antara 0 - 15 meter sedangkan akuifer dalam pada tiap titik berkisar antara 40 - 90 meter. Ketebalan akuifer pada daerah penelitian berkisar antar $(2-40)$ meter. Penyebaran akuifer airtanah pada daerah penilitian menyebar hampir ke seluruh daerah penelitian (Silva, 2016).

\section{Kesimpulan}

Berdasarkan hasil pengukuran dan pendugaan geolistrik yang dilakukan di wilayah pesisir Kecamatan Bontobahari, Kabupaten Bulukumba disimpulkan bahwa:

- Analisis, interpretasi dan korelasi penampang resistivity pengukuran geolistrik dan kenampakan lapangan menunjukkan bahwa lapisan pembawa air tanah adalah diduga pada tufa dan batupasir dengan range resistivity 5.69-196 Ohm.m, karena kedua batuan ini memiliki sifat porous yang baik sehingga dapat bertindak sebagai lapisan akuifer.
- Tufa yang merupakan batuan kontak dengan batugamping dapat menyimpan air dengan baik, namun dapat mengandung air payau yang merupakan hasil infiltrasi air tanah dari batugamping.

\section{Daftar Pustaka}

Amin, Shadiq Ahmad. (2016). Rancang bangun Prototipe Alat Ukur Resistivitas Tanah. Skala Labolatorium. Matematika dan Ilmu Pengetahuan Alam Unhas. Makassar.

Azhar dan Gunawan Handayani. (2003). Penerapan Metode Geolistrik Konfigurasi Schlumberger untuk Penentuan Tahanan Jenis Batubara. Institut Teknologi Bandung. Bandung.

Pinder, G. F. \& Celia, M. A. (2006) Subsurface Hydrology. New York: John Wiley and Sons.

Purnama, S. (2010). Hidrologi Airtanah. Yogyakarta : Kanisius.

Reynolds, J.M. (1998). An Introduction to Applied and Enviromental Geophysics. New York : John Wiley \& Sons.

Silva, Domingos da (2016). Pendugaan penyebaran akuifer dan zona air tanah menggunakan metode geolistrik konfigurasi Schlumberger Daerah Kajang, Herlange, Ujungloe, dan Bontobahari Kabupaten Bulukumba, Sulawesi Selatan. Tesis, UPN Veteran, Yogyakarta.

Telford, W.M. Geldart, L.P. Sheriff, R.E. Keys, D.A. (1990). Applied Geophysics. Cambridge University Press, London.

van Nostrand, Robert, G. \& Kenneth, L Cook. (1966). Interpretation of Resistivity Data. Washington: Geological Survey. 